\title{
EFFECT OF 70\% ETHANOL EXTRACT OF ORTHOSIPHONIS STAMINEUS BENTH LEAVES ON THE PHARMACOKINETIC PARAMETERS OF FUROSEMIDE IN MALE WHITE RATS
}

\author{
RIANA MAYA OKTAVIANI, SANTI PURNA SARI*, YAHDIANA HARAHAP
}

Department of Pharmacy, Faculty of Pharmacy, Universitas Indonesia, Depok, Indonesia. Email: santisari@farmasi.ui.ac.id

Received: 21 April 2017, Revised and Accepted: 18 August 2017

ABSTRACT

Objective: This study aimed to observe the effect of the $70 \%$ ethanol extract of Orthosiphonis stamineus Benth leaves on the pharmacokinetic parameters of furosemide in white male rats.

Methods: 18 Sprague-Dawley male rats were divided into three groups: The normal control group was given only $1 \%$ carboxymethyl cellulose, the furosemide group was given $7.2 \mathrm{mg} / 200 \mathrm{~g}$ body weight (BW) suspension of furosemide, and the combination group was given $700 \mathrm{mg} / \mathrm{kg}$ BW suspension of the $70 \%$ ethanolic extract of 0 . stamineus Benth leaves for 4 days followed by a $7.2 \mathrm{mg} / 200 \mathrm{~g}$ BW suspension of furosemide. On the $4^{\text {th }}$ day of treatment, we performed orbital sinus blood sampling on the eyes of the rats and analyzed the levels of furosemide in plasma using highperformance liquid chromatography.

Results: Therefore, the results showed that the administration of the $70 \%$ ethanol extract of 0 . stamineus Benth leaves improves the pharmacokinetic parameters of furosemide on $\mathrm{Cp}_{\max }$ and the area under the curve $(\mathrm{p}<0.05)$.

Conclusion: This study concludes that the $70 \%$ ethanol extract of 0 . stamineus Benth leaves improves the pharmacokinetic parameters of furosemide in white male rats.

Keywords: Cat's whiskers leaves, Furosemide, Orthosiphonis stamineus Benth, Pharmacokinetic, 70\% ethanolic extract.

(C) 2017 The Authors. Publishedby Innovare Academic Sciences Pvt Ltd. This is an open accessarticle under the CC BY license (http://creativecommons. org/licenses/by/4. 0/) DOI: http://dx.doi.org/10.22159/ijap.2017.v9s1.28_33

\section{INTRODUCTION}

Furosemide is an anthranilic acid derivative drug included in powerful diuretics. Based on the research conducted by Bragatto et al. [1], a single dose of $40 \mathrm{mg}$ furosemide given orally produced significant results in increasing the volume of urine and had a pharmacokinetics ratio interval of $\mathrm{C}_{\max }(93.63-121.92 \%)$, area under the curve $\left(\mathrm{AUC}_{0-\mathrm{t}}\right)$ (96.80-115.72\%), and AUC $_{0-\infty}(98.45-117.43 \%)$. Another study mentions that the administration of furosemide with a dose of $8 \mathrm{mg} / 200 \mathrm{~g}$ body weight (BW) produced $\mathrm{AUC}_{0-\infty} 13.52 \pm 52.29 \mu \mathrm{g} / \mathrm{mL}$ $\mathrm{hr}$ with $\mathrm{C}_{\max } 22: 34 \pm 4: 39 \mu \mathrm{g} / \mathrm{mL}$ [2]. Indonesian herbal medicine has been used for hundreds of years, long before the advent of modern medicine that involves a diagnostic laboratory and chemicals [3]. The results of basic medical research in 2010 showed that about 59.12\% of Indonesia's population consumes herbs [4]. Cat's whiskers is a medicinal plant that has been empirically shown to act as a diuretic. Tensigard ${ }^{\circledR}$ is a phytopharmacological preparation containing extracts of cat's whiskers leaves combined with celery extract and is used as an antihypertensive due to its diuretic properties.

The use of cat's whiskers leaf extract and furosemide at the same time can cause a pharmacokinetic interaction that can increase or decrease furosemide levels in plasma. As a result, drug toxicity and drug effectiveness may also increase or decrease [5]. The diuretic effect of cat's whiskers leaf extract is demonstrated by the inhibition of adenosine receptor $\mathrm{A}_{1}$, which will inhibit sodium reabsorption in the proximal tubules [6], and the diuretic mechanism of furosemide diuretic inhibits reabsorption of electrolytes $\mathrm{Na}^{+} / \mathrm{K}^{+} / 2 \mathrm{Cl}^{-}$in the ascending limb of the loop of Henle in the thick epithelium section. The diuretic effect of cat's whiskers leaf extract and furosemide was similarly with inhibiting sodium reabsorption in the nephron [7]. The changes in the levels of the combined drugs will affect the pharmacokinetic parameters of furosemide, and this study observes the influence of cat's whiskers leaf extract on the pharmacokinetic parameters of furosemide in white male rats using blood plasma samples.

\section{MATERIALS AND METHODS}

Materials

The material sample used in this study was the $70 \%$ ethanol extract of cat's whiskers leaf (Orthosiphonis stamineus Benth.) obtained from the Research Center for Spices and Medicinal Plants. Determination of cat's whiskers leaf was conducted by the Indonesian Institute of Sciences, Bogor Botanical Gardens. Animals used in this study were 30 Sprague-Dawley rats: 12 samples for the optimization of timing and 18 for the actual test. The rats were male, approximately 3 months old and approximately $200 \mathrm{~g}$ in weight, and were obtained from the Institut Pertanian Bogor. The chemicals used include furosemide (Kimia Farma), furosemide standard (BPFI), propranolol HCl (BPFI), carboxymethyl cellulose (CMC) (Brataco Chemical), methanol (highperformance liquid chromatography [HPLC] grade, Merck), phosphoric acid (85\%) (Merck), ethyl acetate (Merck), human blood plasma from Palang Merah Indonesia, Aqua Bidest distilled water, food standards for test animals, anhydride acetic acid, Mayer's reagent, Dragendorff's reagent, Bouchard's reagent, Molisch's reagent, iron (III) chloride reactant solution, hydrochloric acid, zinc powder, and magnesium powder.

\section{Instruments}

The instruments used in this study were stomach probes, syringes (Terumo), animal scales, an analytical balance (Ohaus), microhematocrit capillary tubes, a set of HPLC LC-10AD VP tools (Shimadzu) consisting of a pump, an injector, $\mathrm{C}_{18}$ column of RP-18e (Waters, Sunfire TM $5 \mu \mathrm{m}$; $250 \times 4.6 \mathrm{~mm}$ ), detector SPD-20A ultraviolet-visible (UV-Vis), DGU-12A degasser, SCL-10A VP controller, and data processing on a computer, UV-1601 (Shimadzu), pH meter (Eutech pH 700), vortex (Maxi Mix II), microcentrifugator (Spectrafuge $16 \mathrm{M}$ ), refrigerator (Lab Tech), centrifugator (Digisystem), evaporator (Caliper), microtube, centrifuge tubes, $0.45 \mu \mathrm{m}$ membrane filter, micropipette and pipette (blue tip/ yellow tip), reaction tube, test tube rack, vaporizer cup, beaker (Pyrex), spatula, stir bar, measuring glass (Pyrex), and flask (Pyrex). 
Test material preparation

Preparation of the test material included producing CMC solution of $1 \%$, producing the furosemide suspension, producing the $70 \%$ ethanol extract suspension of cat's whiskers leaves extract, producing a mobile phase of methanol-water (50:50) that adjusted to phosphoric acid $(85 \%)$ at $\mathrm{pH}$ of 3.0 , producing furosemide solution for optimization, producing propranolol $\mathrm{HCl}$ solution for internal standard solution, and producing furosemide solutions for calibration curve.

\section{Qualitative phytochemical screening of $70 \%$ ethanol extract from cat's whiskers leaves}

Qualitative phytochemical screening of the 70\% ethanol extract of cat's whiskers leaves consisted of organoleptic, alkaloid, phenol, flavonoids, and terpenes identification. Organoleptic evaluation was conducted by observing the form, color, and odor of the extract [8]. Alkaloids were identified with Dragendorff's, Mayer's, and Bouchard's reagent solutions. Alkaloid was indicated by the orange precipitate through Dragendorff's reagent, the yellow precipitate through Mayer's reagent, and the reddishbrown sediment through Bouchard's reagent [9]. Phenol was identified by adding 3-4 drops of iron (III) chloride reactant solution. Phenol is shown in the formation of a bluish-black color [10]. Flavonoids were identified by the Shinoda test [9]. Identification of terpene was accomplished by the addition of ether, which was then allowed to evaporate, then added 2 drops of acetic acid anhydride, and 1 drop of sulfuric acid [9].

\section{Test animal preparation}

Before treatment, rats were acclimatized for 2 weeks in an animal cage at the Pharmacology-Toxicology Laboratory of the Faculty of Pharmacy, University of Indonesia. The test used 18 male rats with six rats in each group. In the experiment, rats were randomly divided into three groups: The normal control group, the furosemide group, and the extract furosemide combination group. After acclimatization, the rats were given an appropriate treatment according to the group, with the time of treatment tailored to the timing of optimization results. A dose of $70 \%$ of ethanol extract from cat's whiskers leaves is the most widely used dose for diuretic purposes, which is about $700 \mathrm{mg}$ / $\mathrm{kg}$. The furosemide dose was an empirical dose most commonly used in society to treat diuretic problems and is measured at about $40 \mathrm{mg} /$ human. The furosemide dose for rats was approximately $40 \times$ $0.018 \times 10=7.2 \mathrm{mg} / 200 \mathrm{~g}$ rat BW.

\section{Dosage and time optimization}

12 of the test animals were divided into four groups of three test animals. Group 1 was the normal group, Group 2 was given the suspension of furosemide at a dose of $7.2 \mathrm{mg} / 200 \mathrm{~g}$ BW orally, Group 3 received the suspension of $70 \%$ ethanol extract of cat's whiskers leaves at a dose of $700 \mathrm{mg} / \mathrm{kg}$ given orally for 4 days followed by the suspension of furosemide at a dose of $7.2 \mathrm{mg} / 200 \mathrm{~g} \mathrm{BW}$, and Group 4 was given the suspension of $70 \%$ ethanol extract of cat's whiskers leaves at a dose of $700 \mathrm{mg} / \mathrm{kg}$ orally for 7 days followed by the suspension of furosemide at a dose of $7.2 \mathrm{mg} / 200 \mathrm{~g} \mathrm{BW}$ (Table 1). Before administering the furosemide, we gave the rats warm distilled water $(25 \mathrm{ml} / \mathrm{kg})$ as a loading dose. The parameters measured were the increases in the average urine volume of each test group.

\section{Examination of furosemide levels in the blood}

Measurements of the furosemide content of the $70 \%$ cat's whiskers ethanol extract and the furosemide levels in blood plasma were performed using HPLC. The study began by fasted the test animals for $12 \mathrm{hrs}$ before administering the extract and furosemide on the last day of treatment. This treatment aims to condition the animal test and to minimize drug interactions with other substances potentially present in the rats.

Blood was drawn from the orbital sinus of the rat's eye after administration of the furosemide suspension. Blood collected in a microtube, and already given heparin was centrifuged for 10 minutes at $3500 \mathrm{rpm}$; then, the supernatant was transferred to a new microtube. Put $250 \mathrm{~mL}$ plasma, add $50 \mathrm{~mL}$ of internal standard, and then extracted.
Table 1: Group division and animal testing

\begin{tabular}{ll}
\hline Group & Treatment \\
\hline Control & Provision of CMC $1 \%$ \\
Furosemide & Provision of furosemide suspension \\
& $7.2 \mathrm{mg} / 200 \mathrm{~g} \mathrm{BW}$ \\
Combination & Provision of $70 \%$ cat's whiskers ethanol \\
& extract $700 \mathrm{mg} / \mathrm{kg} \mathrm{BW}+\mathrm{furosemide}$ \\
& suspension $7.2 \mathrm{mg} / 200 \mathrm{~g} \mathrm{BW}$ \\
\hline
\end{tabular}

CMC: Carboxymethyl cellulose, BW: Body weight

The solution from the extraction $(20 \mathrm{~mL})$ was injected to HPLC by chromatographic conditions chosen using C18 column $(250 \times 4.6 \mathrm{~mm}$, $5 \mu \mathrm{m}), \mathrm{UV}$-Vis detector [11]. Measurements were taken at 0, 0.5, 1, 1.5, $2,2.5,3,4,8$, and $10 \mathrm{hrs}$ after administration of the furosemide.

\section{Optimization of condition analysis}

Wavelength analysis involved the use of a UV-Vis spectrophotometer at a concentration of $10 \mu \mathrm{g} / \mathrm{mL}$. Optimization of the mobile phase ratio included three comparisons: Methanol-water (50:50 v/v) pH 3.0, methanol-water $(55: 45 \mathrm{v} / \mathrm{v}) \mathrm{pH} 3.0$, and methanol-water $(60: 40 \mathrm{v} / \mathrm{v})$ $\mathrm{pH} 3.0$, using solutions containing $10 \mathrm{mg} / \mathrm{mL}$ of furosemide and $100 \mathrm{mg} /$ $\mathrm{mL}$ of propranolol $\mathrm{HCl}$. The $\mathrm{pH}$ modification of the mobile phase was at $\mathrm{pH} 2.8, \mathrm{pH} 3.0$, and $\mathrm{pH}$ 3.2. Further modification of the flow rate was 0.8 , 1.0 , and $1.2 \mathrm{~mL} / \mathrm{min}$. Each optimization was compared to the retention time $\left(t_{R)}\right.$, the peak area $(A)$, tailing factor $\left(T_{f}\right)$, the value of the number of theoretical plates $(\mathrm{N})$, HETP, and the resolution (R). The coefficient of variation $(\mathrm{CV})$ was obtained after 6 repetitions of the test.

\section{Optimization of extraction method}

$250 \mu \mathrm{L}$ of plasma containing $10 \mu \mathrm{g} / \mathrm{mL}$ of furosemide in a centrifugation tube added $50 \mu \mathrm{L}$ containing $50 \mu \mathrm{g} / \mathrm{mL}$ propranolol $\mathrm{HCl}$, and then, vortex a 10 seconds. The mixture was added ethyl acetate as much as 10 times of the mixture, and then, vortex for 1 minute. The mixture was centrifuged for 20 minutes at $3000 \mathrm{rpm}$. The supernatant was taken and evaporated with nitrogen gas for 15 minutes at $60^{\circ} \mathrm{C}$. The residue was dissolved in $200 \mathrm{~mL}$ of the mobile phase, and as much as, $20 \mathrm{~mL}$ of the solution was injected into the HPLC instrument on the condition of the selected analysis. Optimization time of vortex was 30 seconds, 1 minute, and 1.5 minutes. Furthermore, optimization time of centrifugation was 10 minutes and 20 minutes. Each optimization was performed by observing the maximum peak of the analysis.

\section{Validation method}

\section{Producing calibration curve and linearity test}

A calibration curve was created with plasma comprising one blank sample (plasma without raw), a zero sample (plasma raw), and 7 concentration gradients of calibration curve: $1,5,10,15,20,30$, and $40 \mu \mathrm{g} / \mathrm{mL}$. Each concentration for the calibration curve was added raw in as much as $50 \mu \mathrm{L}$ from $50 \mathrm{ppm}$ and extracted as in the sample. Linearity was determined by calculating the correlation coefficient of the linear regression of the calibration curve. In addition, the calculated value \% difference for each produced calibration curve with the requirements should not be more than $\pm 15 \%$, except for the lowest quantitation limit determination (LLOQ) solution, which should not be more than $\pm 20 \%$.

\section{LLOQ}

We prepared a standard furosemide solution in plasma at LLOQ concentration (based on the calculation of the calibration curve series) and then added internal standard and prepared as in the sample. The injection was repeated 5 times. From the measurement data, we then calculated the value \% difference and $\mathrm{CV}$ with the requirements of not more than $20 \%$. If the solution at the tested concentration met the requirements, then it was retested by half of the initial concentration. This process was performed until the lowest concentration was obtained that still met the requirements, otherwise known as LLOQ. 


\section{Accuracy and precision}

We prepared a plasma containing the solution at LLOQ concentrations and at low (QCL), moderate (QCM), and high (QCH) concentrations.

- $\quad \mathrm{QCL}=3 \times$ concentration of LLOQ $(1 \mu \mathrm{g} / \mathrm{mL})=3 \mu \mathrm{g} / \mathrm{mL}$,

- $\mathrm{QCM}=50 \%$ in the calibration curve concentration range $=20 \mathrm{mg} / \mathrm{mL}$,

- $\mathrm{QCH}=75 \% \times$ upper limit of quantification $(40 \mu \mathrm{g} / \mathrm{mL})=30 \mu \mathrm{g} / \mathrm{mL}$.

Each concentration received the standard preparation of $50 \mathrm{~mL}$. Tests were repeated 5 times for each concentration intraday (within run) and interday (between run) for at least 2 different days with a minimum of three test iterations. We then calculated the \% difference as the parameter of accuracy and $\% \mathrm{CV}$ as a precision parameter. The $\%$ difference and CV value should not exceed $\pm 20 \%$ of the sample LLOQ and should not exceed $\pm 15 \%$ for all quality control samples.

\section{Pharmacokinetic parameters of furosemide in blood}

Pharmacokinetic parameters calculated were the absorption rate constant $(\mathrm{Ka})$, the peak time $\left(\mathrm{t}_{\max }\right)$, the peak plasma concentration $\left(\mathrm{Cp}_{\max }\right)$, the elimination rate constant $(\mathrm{Ke})$, the half-life $\left(\mathrm{t}_{1 / 2}\right)$, the volume of distribution (Vd), the clearance ( $\mathrm{Cl}$ ), and the AUC. Each of these pharmacokinetic parameters was analyzed using SPSS to determine the normality as well as the significance of the data.

\section{RESULTS AND DISCUSSIONS}

Phytochemical screening of the $70 \%$ ethanol extract of cat's whiskers leaves

Organoleptic evaluation is useful for knowing the characteristics of cat's whiskers leaf extract. Observations showed that the $70 \%$ ethanol extract of cat's whiskers leaf was in the form of a slightly thick liquid, had a distinctive smell, and was a blackish-green color. The yield produced in the simplex process of the cat's whiskers plant was $7.43 \%$. Furthermore, a phytochemical screening process was conducted to determine the class of bioactive compounds contained in the extract. Phytochemical screening conducted at the Research Institute for Spices and Medicinal Plants showed positive results for alkaloids, phenols, flavonoids, and terpenes. Phytochemical screening was also performed at the Phytochemistry Laboratory of the Faculty of Pharmacy, UI, and the results are shown in Table 2.

\section{Time optimization of the $70 \%$ ethanol extract of cat's whiskers} leaves

Based on the average, we can see that the volume mean of urine was the most in the group given the $70 \%$ ethanol extract of cat's whiskers leaves for 4 days followed by the furosemide dose on day 4 . The first urine volume measurement was $11.166 \mathrm{~mL}$; at the $2^{\text {nd }} \mathrm{hr}$, the volume rose to $15.833 \mathrm{~mL}$; at the $3^{\text {rd }} \mathrm{hr}$, it measured at $17.50 \mathrm{~mL}$; and the amount remained stable from 4 to $6 \mathrm{hrs}$ (at a volume of $18.50 \mathrm{~mL}$ ). Time for 4 days of the extract was used as the actual test. Optimization results for the average volume of rat urine for $6 \mathrm{hrs}$ are shown in Table 3.

\section{Optimization of condition analysis}

The optimum wavelength selected for furosemide analysis was $236 \mathrm{~nm}$. This wavelength was chosen because it is the greatest absorption of furosemide. In mobile phase ratio selection, methanol-water $(60: 40 \mathrm{v} / \mathrm{v})$ $\mathrm{pH} 3.0$ was used as the first mixture of mobile phase. In this mobile phase composition, furosemide and propranolol $\mathrm{HCl}$, respectively, have a retention time of 5.472 and 2.900 minutes; theoretical plates $(\mathrm{N})$ of 1851.523 and 1258.122; HETP of 0.0135 and 0.0199 ; tailing factor $\left(\mathrm{T}_{\mathrm{f}}\right)$ of 1.641 and 0.880 ; and a resolution of 6.154. Then, that mobile phase is modified to methanol-water $(55: 45 \mathrm{v} / \mathrm{v}) \mathrm{pH} 3.0$ and methanol-water $(50: 50 \mathrm{v} / \mathrm{v}) \mathrm{pH} 3.0$. The composition of methanol-water $(55: 45 \mathrm{v} / \mathrm{v})$, furosemide and propranolol $\mathrm{HCl}$, respectively, had a retention time of 7.405 and 3.043 minutes; theoretical plates $(\mathrm{N})$ of 2514.007 and 1515.980; HETP of 0.0099 and 0.0165 ; tailing factor $\left(\mathrm{T}_{\mathrm{f}}\right.$ ) of 1.695 and 1.750; and resolution of 9.658. The composition of methanol-water (50:50 v/v), furosemide and propranolol $\mathrm{HCl}$, respectively, had a retention time of 10.677 and 3.340 minutes; theoretical plates $(\mathrm{N})$ of 4002.193 and 2926.168; HETP of 0.0062 and 0.0085 ; tailing factors $\left(T_{f}\right)$ of 1.689 and 1.874 ; and resolution of 15.914 .

The $\mathrm{pH}$ optimization of mobile phase, methanol-water $(50: 50 \mathrm{v} / \mathrm{v})$ $\mathrm{pH} 2.5$ showed that retention time of furosemide and propranolol $\mathrm{HCl}$ was 9.291 and 4.040 minutes, respectively, whereas the composition of methanol-water (50:50 v/v) pH 3.5 retention time of furosemide and propranolol $\mathrm{HCl}$ was 13.257 and 3.451 minutes, respectively. The flow rate was used as an initial condition, and it was $1.0 \mathrm{~mL} /$ minute. The flow rate of $1.0 \mathrm{~mL} /$ minute obtained retention time of furosemide and propranolol $\mathrm{HCl}$, respectively, was 10.577 and 3.335 minutes. The flow rate of $1.2 \mathrm{~mL} /$ minute retention time in furosemide and propranolol $\mathrm{HCl}$, respectively, was 9.038 and 2.844 minutes, whereas the flow rate of $0.8 \mathrm{~mL} /$ minute had a retention time in furosemide and propranolol $\mathrm{HCl}$, respectively, of 13.449 and 4.713 minutes and resolution of 14.508 $(\geq 1.5) ; \mathrm{T}_{\mathrm{f}}=1.527(\leq 2)$; and $\mathrm{N}=3726.252(\geq 2.000)$. This study showed that $\% \mathrm{CV}$ was $<2.0 \%$. The results obtained by each system suitability test performed yielded a $\mathrm{CV}$ value of $<2.0 \%$. Time analysis of each injection was 15 minutes.

\section{Optimization of extraction method}

Data optimization with a vortex agitation time of 30 seconds resulted in a furosemide area of 304.907; vortex agitation for 1 minute resulted in a furosemide area of 318.954; and vortex agitation for 1.5 minutes resulted in a furosemide area of 285.781. Playback of time optimization data by centrifugation, namely, the screening of 10 minutes, showed a

Table 2: Results of phytochemical screening of the $70 \%$ ethanol extract of cat's whiskers leaves

\begin{tabular}{lll}
\hline Identification & Results & Information \\
\hline Alkaloids & Orange precipitate (Dragendorff's reagent), yellow (Mayer's reagent), and & Positive, contains alkaloids \\
& reddish-brown (Bouchard's reagent) & Positive, contains phenol \\
Phenol & Bluish-black color & Positive, contains flavonoids \\
Flavonoids & Red color formed in Shinoda reaction & Positive, contains terpenes \\
Terpene & Color change occurred & \\
\hline
\end{tabular}

Table 3: Average volume of rat urine for $6 \mathrm{hrs}$ in a preliminary test

\begin{tabular}{|c|c|c|c|c|c|c|}
\hline \multirow[t]{2}{*}{ P Treatment group } & \multicolumn{6}{|c|}{ The average volume of urine at hours of $\mathrm{mL} \pm \mathrm{SD}$} \\
\hline & 1 & 2 & 3 & 4 & 5 & 6 \\
\hline Control & $2.2 \pm 1.0$ & $5.7 \pm 2.5$ & $6.3 \pm 2.1$ & $6.8 \pm 1.6$ & $6.8 \pm 1.6$ & $6.8 \pm 1.6$ \\
\hline Furosemide & $8.0 \pm 1.0$ & $15.7 \pm 1.6$ & $15.7 \pm 1,6$ & $15.7 \pm 1.6$ & $15.7 \pm 1.6$ & $15.7 \pm 1.6$ \\
\hline Combination for 4 days & $11.2 \pm 3.2$ & $15.8 \pm 2.1$ & $17.5 \pm 1.3$ & $18.5 \pm 1.0$ & $18.5 \pm 1.0$ & $18.5 \pm 1.0$ \\
\hline Combination for 7 days & $9.8 \pm 1.4$ & $13.2 \pm 1.3$ & $15.5 \pm 1.3$ & $16.0 \pm 0.5$ & $16.0 \pm 0.5$ & $16.2 \pm 0.8$ \\
\hline
\end{tabular}

Information: Control=With CMC 1\%; furosemide=Furosemide of $7.2 \mathrm{mg} / 200 \mathrm{~g} \mathrm{BW}$, combination=Extract of Cat's whiskers leaf of $700 \mathrm{mg} / \mathrm{kg}+\mathrm{furosemide}$

$7.2 \mathrm{mg} / 200$ g BW. CMC: Carboxymethyl cellulose, BW: Body weight, SD: Standard deviation 
furosemide area of 326.004, while the playback for 20 minutes showed a furosemide area of 337.592. This study showed that $\% \mathrm{CV}$ was $<2.0 \%$. The results obtained by each system suitability test performed yielded a CV value $<2.0 \%$

\section{Validation of partial analysis methods}

\section{Producing calibration curve and linearity test}

The calibration curve consists of a plasma blanket (plasma without analyte and internal standard), zero sample (plasma with internal standard), and non-zero plasma (plasma with analyte and internal standard) of 7 concentrations: 1.0, 5.0, 10.0, 15.0, 20.0, 30.0, and $40.0 \mu \mathrm{g} / \mathrm{mL}$. The calibration curve produces a linear regression equation in the form $\mathrm{y}=0.1737 \mathrm{x}+0.0109$ with $\mathrm{r}^{2}=0.999$; where $\mathrm{x}$ is the concentration of furosemide $(\mathrm{mg} / \mathrm{mL})$ and $\mathrm{y}$ is the PAR between furosemide and propranolol $\mathrm{HCl}$ raw. Based on the data, the $\mathrm{CV}$ value obtained was no more than $> \pm 15 \%$ for all concentrations, including the LLOQ.

\section{$L L O Q$}

In bioanalytics, LLOQ values should cover at least $1 / 20$ of the maximum concentration $\left(\mathrm{C}_{\max }\right.$ of analytes in plasma. In this study, concentrations of $1.0 \mathrm{ug} / \mathrm{mL}$ were used to limit LLOQ temporary, and this concentration is repeated as many as five replicas. The value \% difference and CV at concentrations of $1.0 \mathrm{mg} / \mathrm{mL}$ still met the criteria for accuracy and precision of $< \pm 20 \%$. We then diluted half of the concentration of $0.5 \mathrm{mg} / \mathrm{mL}$ and made five identical samples. The value $\%$ difference and $\mathrm{CV}$ generated at a concentration of $0.5 \mathrm{mg} / \mathrm{mL}$ did not meet the criteria for accuracy and precision, so the LLOQ was used as a concentration limit of $1.0 \mathrm{mg} / \mathrm{mL}$.

\section{Accuracy and precision}

Accuracy and precision were tested by intra- and inter-days. The intraday accuracy measurement values obtained for LLOQ concentration \% difference ranged from $-13.25 \%$ to $-19.27 \%$, and for the QC concentration, it ranged from $-1.50 \%$ to $-19.27 \%$. For the intraday precision measurements, we obtained a $\mathrm{CV}$ value of $<4.75 \%$ for LLOQ and QC concentrations. For the interday measurement accuracy for the LLOQ concentration, we obtained a range of $\%$ difference from $-11.66 \%$ to $+19.27 \%$, and for the QC concentration, the range $\%$ difference was $-0.68 \%$ to $+14.96 \%$. The measurement of the interday precision was a $\mathrm{CV}$ value of $<5.79 \%$. The value $\%$ difference and $\mathrm{CV}$ for both intraday and interday met accuracy and precision standards.

\section{Pharmacokinetic analysis of furosemide in rat blood plasma}

The rat plasma obtained was analyzed using HPLC with previously validated analysis conditions. The plasma furosemide concentration obtained in the administration of the single and combined furosemide with the $70 \%$ ethanol extract of cat's whiskers was calculated by pharmacokinetic parameters. The mean of pharmacokinetic parameter data obtained can be seen in Table 4

\section{Description}

The time optimization of a comparative analysis of selected mobile phases is a mobile phase composition of methanol-water mixture $(50: 50 \mathrm{v} / \mathrm{v})$ that adjusted by phosphoric acid to a $\mathrm{pH}$ of 3.0. The selection was based on the retention time and resolution between the analyte and internal standard. In this mobile phase composition, separation and retention time of internal standard was a little longer than the mobile phase of methanol-water (55:45) and methanol-water (60:40). In the mobile phase of methanol-water $(50: 50 \mathrm{v} / \mathrm{v}) \mathrm{pH} 3.0$, the peak of the analyte on the chromatogram was more pointed and had a better resolution than $\mathrm{pH} 2.5$ and $\mathrm{pH}$ 3.5. The flow rate used for analysis was $0.8 \mathrm{~mL} /$ minute with resolution was $14.508(\geq 1.5) ; \mathrm{T}_{\mathrm{f}}=1.527(\leq 2)$; and $\mathrm{N}=3726.252(\geq 2.000)$, that qualifies the method of analysis. At a flow rate of $1.0 \mathrm{~mL} / \mathrm{min}$ and $1.2 \mathrm{~mL} / \mathrm{min}$, the retention time of propranolol $\mathrm{HCl}$ (internal standard) allowed peak plasma impurities that would interfere with the peak of the analyte.

The extraction method used was a liquid-liquid extraction method. This method was chosen because it results in fewer impurities than
Table 4: The mean of pharmacokinetic parameters in the treatment group $( \pm \mathrm{SD}$ values)

\begin{tabular}{llll}
\hline $\begin{array}{l}\text { Pharmacokinetic } \\
\text { parameters }\end{array}$ & Unit & Furosemide & Combination \\
\hline $\mathrm{Ka}$ & ${ }^{-1} \mathrm{hr}$ & $0.96 \pm 0.08$ & $0.88 \pm 0.07$ \\
$\mathrm{t}_{\max }$ & $\mathrm{hr}$ & $2.5 \pm 0$ & $2.5 \pm 0$ \\
$\mathrm{Cp}_{\max }$ & $\mathrm{ug} \mathrm{mL}$ & $13.63 \pm 2.01^{*}$ & $18.16 \pm 0.81^{*}$ \\
$\mathrm{To}_{\mathrm{t}}$ & $-1 \mathrm{hr}$ & $0.70 \pm 0.22$ & $0.78 \pm 0.04$ \\
$\mathrm{t}_{1 / 2}$ & $\mathrm{hr}$ & $3.03 \pm 0.80$ & $2.54 \pm 0.28$ \\
$\mathrm{Vd}$ & $\mathrm{mL}$ & $537.90 \pm 81.71^{*}$ & $397.06 \pm 17.22^{*}$ \\
$\mathrm{Cl}$ & $\mathrm{hrs} \mathrm{mL^{-1 }}$ & $364.64 \pm 100.28$ & $308.51 \pm 13.23$ \\
$\mathrm{AUCC}$ & $\mathrm{ug} \mathrm{mL} \mathrm{m}^{-1} \mathrm{hr}$ & $46.92 \pm 4.91^{*}$ & $62.86 \pm 3.99^{*}$ \\
$\mathrm{AUC}_{\mathrm{t}-\infty}$ & $\mathrm{ug} \mathrm{mL} \mathrm{m}^{-1} \mathrm{hr}$ & $12.42 \pm 1.22$ & $14.37 \pm 2.65$ \\
$\mathrm{AUC}_{0-\infty}$ & $\mathrm{ug} \mathrm{mL} \mathrm{m}^{-1} \mathrm{hr}$ & $59.34 \pm 4.27^{*}$ & $77.23 \pm 6.43^{*}$ \\
\hline
\end{tabular}

*Indicates significance value $<0.05$, that means on the two groups have

significantly different values. AUC: Area under the curve, SD: Standard deviation

the protein precipitation method. Ether or ethyl acetate can be used for drug extraction from plasma, but on this study, ethyl acetate offers the cleanest chromatogram compared to ether use. The time optimization of agitation with the vortex showed that the longer the shaking time, the more analytes and raw were extracted, so a greater response peak area was produced; however, if shaken for too long, fewer analytes and raw were extracted, so the response peak area produced was much smaller. Therefore, 1 minute shuffling time was chosen, because at that time, it provides the broadest peak response. Time optimization by centrifugation showed that the longer centrifugation would result in better separation so that the generated response peak area would be greater, 20 minutes for centrifugation was chosen. In the method validation, calibration curve measurements, accuracy, and precision values were obtained as $\mathrm{CV}$ and \% difference in accordance with the requirements for all concentrations, including LLOQ.

The results of pharmacokinetic analysis of furosemide in the blood plasma of white rats showed that administration of a combination of $70 \%$ ethanol extract of cat's whiskers leaves and furosemide did not result in a significant decrease $(p>0.05)$ in the rate of absorption but also did not significantly increase the rate of elimination. An increase in the rate of elimination means more drugs were being released from the body. This corresponds to the diuretic mechanism of increasing urine volume. The time of plasma concentration peak did not change, while the half-life decreased. Rises in value elimination rate cause a decline in how long the drug is present in the body [12].

Decreased clearance did not differ significantly. Clearance value is directly proportional to the volume of distribution and the elimination rate [12]. The decline in value is due to the volume of distribution clearance, which also decreased significantly while the elimination rate increased. The volume of distribution shows the amount of drug distribution in the body. The volume of distribution is also related to the amount of drug in the plasma. If the volume of distribution increases, the drug concentration in the plasma will be small and otherwise [12]. The peak plasma concentration increased significantly $(\mathrm{p}<0.05)$, as well as the AUC. This increase indicates an increase in the plasma concentration of therapeutic furosemide. Increasing concentrations of furosemide are still relatively safe because it does not reach a toxic level. Under the U.S. Food and Drug Administration and the World Health Organization guidelines on bioequivalence, furosemide plasma concentrations reach toxicity in the interval of $25-30 \mathrm{mg} / \mathrm{mL}$ [13].

Based on the results of the phytochemical screening, cat's whiskers leaves contain flavonoids, alkaloids, terpenes, and phenols. The increase in pharmacokinetic parameters in male rats caused by the presence of methoxy flavonoids that can induce diuretic through the activity of the adenosine $A_{1}$ receptor antagonist that is involved in the regulation of the flow rate of urine and the excretion of sodium $[14,15]$. Inhibition 
of these receptors would inhibit sodium and water reabsorption in the proximal tubules [6].

Administration together between furosemide, which is a potent diuretic, with $70 \%$ ethanol extract of cat's whiskers leaves can cause interactions that lead to the inhibition of sodium reabsorption in the nephron. Furosemide and flavonoids found in cat's whiskers leaves have similar diuretic properties. Furosemide is a diuretic that inhibits the reabsorption of electrolytes $\mathrm{Na}^{+} / \mathrm{K}^{+} / 2 \mathrm{Cl}^{-}$in the ascending limb of the loop of Henle in the thick epithelial part, and flavonoids found in the cat's whiskers plant can inhibit the reabsorption of sodium and water in the proximal tubules through inhibition of adenosine receptor $A_{1}$ The diuretic effect of cat's whiskers leaves also suspected to be due to the methylripariochromene compound A (MRC-A). MRC-A diuretic effect is shown by an increase in the volume of urine and excretion of $\mathrm{Na}^{+}, \mathrm{K}^{+}$, and $\mathrm{Cl}^{-}$.

\section{CONCLUSION}

Based on these research results, this study concludes that the joint administration of $70 \%$ ethanol extract of cat's whiskers leaves (O. stamineus Benth) and furosemide can improve the pharmacokinetic parameters of furosemide in white male rats, results that were indicated by significant increases $(\mathrm{p}<0.05)$ in peak plasma concentration $\left(\mathrm{Cp}_{\max }\right)$ and AUC.

The authors also recommend performing the further studies on the toxicity of the concurrent use of $70 \%$ ethanol extract of the cat's whiskers plant with furosemide.

\section{REFERENCES}

1. Bragatto MS, Santos MB, Pinto AM, Gomes E, Angonese NT, Viezzer WF, et al. Comparison between pharmacokinetic and pharmacodynamic of single-doses of furosemide $40 \mathrm{mg}$ tablets. J Bioequiv Bioavailab 2011;48:519-32.
2. Soica C, Vari C, Imre S, Gyéresi Á, Dehelean C, Dogaru M. HPLC analysis of furosemide in rat plasma, bioavailability study. Farmacia 2008;56(5):513-20.

3. Muhtadi A, Wibowo MA, Hasanah AN, Muchtaridi M, Musfiroh I. The effect of turmeric extract (Curcuma domestica Val.) on the pharmacokinetic profile of paracetamol in male white Wistar rats. Res J Pharm Biol Chem Sci 2015;6(6):406-14

4. Badan Penelitian dan Pengembangan Kesehatan. Laporan Hasil Riset Kesehatan Dasar (Riskesdas) Indonesia Tahun 2010. Jakarta: Kementerian Kesehatan RI; 2010.

5. Bushra R, Aslam N, Khan AY. Food-drug interactions. Oman Med J 2011;26(2):77-83

6. Welch WJ. Adenosine, Type 1 receptors: Role in proximal tubule Na reabsorption. Acta Physiol (Oxf) 2015;213(1):242-8.

7. Jentzer JC, DeWald TA, Hernandez AF. Combination of loop diuretics with thiazide-type diuretics in heart failure. J Am Coll Cardiol 2010;56(19):1527-34.

8. Departemen Kesehatan Republik Indonesia. Parameter Standar Umum Ekstrak Tumbuhan Obat. Jakarta: Departemen Kesehatan RI; 2000.

9. Departemen Kesehatan Republik Indonesia. Materia Medika Indonesia. Vol. 6. Jakarta: Departemen Kesehatan RI; 1995.

10. Tiwari P, Kumar B, Kaur M, Kaur G, Kaur H. Phytochemical screening and extraction: A review. Int Pharm Sci 2011;1(1):98-106.

11. Sultana N, Arayne MS, Naveed S. RP-HPLC method for simultaneous determination of Captopril and diuretics: Application in pharmaceutical dosage forms and human serum. J Chromatogr Sep Tech 2011;2(2):1-4.

12. Shargel L, Wu-Pong S, Yu AB. Biofarmasetika dan Farmakokinetika Terapan Edisi Kelima. Surabaya: Airlangga University Press; 2012.

13. Granero GE, Longhi MR, Mora MJ, Junginger HE, Midha KK, Shah VP, et al. Biowaiver monographs for immediate release solid oral dosage forms: Furosemide. J Pharm Sci 2010;99(6):2544-56.

14. Ameer OZ, Salman IM, Asmawi MZ, Ibraheem ZO, Yam MF. Orthosiphon stamineus: Traditional uses, phytochemistry, pharmacology, and toxicology. J Med Food 2012;15(8):678-90.

15. Yuliana ND, Khatib A, Link-Struensee AM, Ijzerman AP, RungkatZakaria F, Choi YH, et al. Adenosine A1 receptor binding activity of methoxy flavonoids from Orthosiphon stamineus. Planta Med 2009;75(2):132-6. 